\title{
Normal and Impaired Reflexive Orienting of Attention after Central Nonpredictive Cues
}

\author{
Mario Bonato ${ }^{1}$, Konstantinos Priftis ${ }^{1,2}$, Roberto Marenzi ${ }^{3}$, \\ and Marco Zorzi ${ }^{1}$
}

\begin{abstract}
Recent studies suggest that stimuli with directional meaning can trigger lateral shifts of visuospatial attention when centrally presented as noninformative cues. We investigated covert orienting in healthy participants and in a group of 17 right braindamaged patients ( 9 with hemispatial neglect) comparing arrows, eye gaze, and digits as central nonpredictive cues in a detection task. Orienting effects elicited by arrows and eye gaze were overall consistent in healthy participants and in right brain-
\end{abstract}

\section{INTRODUCTION}

Visual attention is controlled by both top-down factors, such as knowledge, goals, and expectations, and bottomup factors that reflect sensory stimulation. This second form of attentional control is often referred to as stimulus driven to underscore the fact that we are sometimes drawn to stimuli in a sudden and involuntary way, as described by W. James more than 100 years ago. The exogenous control of attention differs from the top-down, endogenous control in a number of important ways. First, the effect of sensory cues does not depend upon experimental instructions or on their reliability in predicting the location of the target (for a review, see Umiltà, 2001). Second, sensory cues produce a processing facilitation at the cued location that appears more rapidly than that produced by cognitive cues (Müller \& Rabbit, 1989). Finally, the early facilitation elicited by sensory cues turns later into a prolonged inhibition of processing (inhibition of return, IOR; Posner \& Cohen, 1984; for a review, see Klein, 2000).

Exogenous and endogenous orienting have been shown to engage partially segregated cortical networks in many neuroimaging studies (for a review, see Corbetta \& Shulman, 2002). Top-down control of attention in humans is thought to be subserved by a network formed by the intraparietal sulcus (IPS) and the frontal eye fields (FEF) bilaterally. In contrast, orienting to sensory stimuli

\footnotetext{
${ }^{1}$ Università di Padova, Italy, ${ }^{2}$ IRCCS San Camillo, Lido-Venezia, Italy, ${ }^{3}$ Centro di Riabilitazione di Conselve, Azienda Ospedaliera di Padova, Padova, Italy
}

damaged patients, whereas digit cues were ineffective. Moreover, patients with neglect showed, at the shortest delay between cue and target, a disengage deficit for arrow cueing whose magnitude was predicted by neglect severity. We conclude that the peculiar form of attentional orienting triggered by the directional meaning of arrow cues presents some features previously thought to characterize only the stimulus-driven (exogenous) orienting to noninformative peripheral cues.

that are unexpected or of potentially high behavioral significance seems to rely on a right hemisphere cortical network that includes the temporo-parietal junction (TPJ) and the ventral frontal cortex (VFC). It has been proposed that the VFC-TPJ network serves as an alerting system that detects behaviorally relevant stimuli in the environment and acts as a "circuit breaker" for the IPS-FEF network, allowing attention to be directed to sensory stimuli that are outside the focus of processing (Corbetta \& Shulman, 2002).

It has long been thought that the only type of cue causing a truly automatic, exogenous orienting of attention is a peripheral sensory cue, such as a light flashed in a nonattended location of the visual field. This view has been in part challenged by a number of studies showing that central "social" cues, such as gazing eyes (e.g., Driver et al., 1999; Friesen \& Kingstone, 1998; for a review, see Frischen, Bayliss, \& Tipper, 2007), can trigger visual orienting although nonpredictive of the spatial position of the target. This finding has been linked to the existence of an innate, domain-specific mechanism for processing eye gaze (Baron-Cohen, 1994), which provides an important source of social information (e.g., indicating the spatial position of interesting events in the environment such as food or danger; Argyle \& Cook, 1976). Indeed, gaze direction is coded even when it is completely irrelevant and potentially interfering with the task (Zorzi, Mapelli, Rusconi, \& Umiltà, 2003). However, other studies have shown that a similar form of orienting can be induced by the meaning of communicative symbols as, for instance, pointing arrows (Ristic \& Kingstone, 2006; Tipples, 2002; Hommel, Pratt, Colzato, 
\& Godijn, 2001). This calls into question the special status of social cues and suggests that a common explanation for these findings is the conveyance of a "directional meaning," regardless of biological relevance (that is, independently of whether the cue consists of gazing eyes or arrows). Initial comparisons between these different cues have shown similar orienting effects in 4-year-old children (Ristic, Friesen, \& Kingstone, 2002), and a selective effectiveness of gaze when cueing was counterpredictive of target position (Friesen, Ristic, \& Kingstone, 2004), but it is still unclear whether these forms of orienting are domain-specific and to what extent they rely on the two attentional systems discussed above.

Orienting after central nonpredictive cueing has been referred to as "reflexive" (e.g., Ristic, Wright, \& Kingstone, 2007), "involuntary" (e.g., Gibson \& Bryant, 2005), or "deictic" (Gibson \& Kingstone, 2006). Here we adopt the term "reflexive orienting" because it has been widely used in the literature. This does not imply any theoretical commitment as to the nature of this form of attentional orienting, which is indeed a controversial matter (for opposing views, see, e.g., Vecera \& Rizzo, 2006; Friesen et al., 2004). Indeed, one aim of the present study is to further investigate this ambiguous form of orienting by testing right brain-damaged patients in addition to healthy participants.

Reflexive orienting has also been described in the case of digit cues (Fischer, Castel, Dodd, \& Pratt, 2003). Irrelevant Arabic numbers oriented attention toward the left in the case of small magnitudes (e.g., 1 or 2), whereas larger numbers (e.g., 8 or 9) triggered rightward shifts of attention. This effect has been ascribed to the automatic activation of a left-to-right spatial representation of numbers (i.e., the "mental number line"; Zorzi, Priftis, Meneghello, Marenzi, \& Umiltà, 2006; Zorzi, Priftis, \& Umiltà, 2002; Dehaene, Bossini, \& Giraux, 1993). In this respect, the direction of the attentional shift would be coherent with the relative position of numbers over the mental number line, that is, leftward for smaller magnitudes and rightward for larger ones.

In the present study, we directly compared the effects of gazing eyes, arrows, and Arabic digits used as taskirrelevant and nonpredictive cues in a detection task. The evidence reviewed above that these types of cue trigger reflexive shifts of attention leads to the fundamental question of whether the underlying cognitive and neural systems engaged by the different cues are the same and to what extent these systems overlap with those involved in the stimulus-driven, exogenous orienting response to peripheral noninformative cues or with the goal-oriented endogenous response to central predictive cues. The participants were healthy adults in Experiment 1 and patients with right brain lesions in Experiment 2. Half of the patients had hemispatial neglect, a neuropsychological syndrome characterized by impaired processing of contralesional space (for a review, see Halligan, Fink, Marshall, \& Vallar, 2003).
The study of neurological patients has the potential to offer insights into the nature of reflexive orienting because a dissociation between impaired exogenous orienting and a relatively spared endogenous orienting is frequently found after right hemisphere damage (Bartolomeo, Sieroff, Decaix, \& Chokron, 2001; Luo, Anderson, \& Caramazza, 1998; Làdavas, Carletti, \& Gori, 1994; Làdavas, Menghini, \& Umiltà, 1994). Indeed, impaired exogenous orienting has been described as "core deficit" in neglect patients (for a review, see Bartolomeo \& Chokron, 2002). Damage to the right-lateralized ventral fronto-parietal network would decrease the capacity to detect unattended sensory events, and thus it would consistently bias competitive interactions between orienting mechanisms in the dorsal parietal cortex (Corbetta, Kincade, Lewis, Snyder, \& Sapir, 2005). It should be noted, however, that patients' asymmetric orienting of attention (i.e., spared ipsilesional vs. impaired contralesional) has been mostly investigated using peripheral informative cueing, which mixes exogenous and endogenous orienting (for a thorough review and meta-analysis, see Losier \& Klein, 2001). Only a minority of previous studies employed peripheral noninformative cueing that elicits a purely exogenous orienting (e.g., Siéroff, Decaix, Chokron, \& Bartolomeo, 2007; Danziger, Kingstone, \& Rafal, 1998; Friedrich, Egly, Rafal, \& Beck, 1998; Làdavas, Carletti, et al., 1994; Farah, Wong, Monheit, \& Morrow, 1989). More importantly for the aim of the present study, voluntary and reflexive components have been confounded in the studies that employed central predictive cueing because arrows were used as cues (Corbetta et al., 2005; Làdavas, Carletti, et al., 1994; Làdavas, Menghini, et al., 1994; Nagel-Leiby, Buchtel, \& Welch, 1990; Posner, Walker, Friedrich, \& Rafal, 1984).

A second feature characterizing patients with right hemisphere damage - and particularly those with neglectis a marked slowness in "disengaging" attention after a right invalid cue (Posner et al., 1984). This bias is known as the "disengage deficit" (hereafter DD) and-crucially four our purposes-it was found to be inconsistent after central informative cues (for a meta-analytic review, see Losier \& Klein, 2001). The magnitude of the DD appears to correlate with lesion size (Losier \& Klein, 2001). With regard to lesion site, the seminal study of Posner et al. (1984) suggested an association between DD and superior parietal lobule (SPL). More recently, Friedrich et al. (1998) compared two groups of patients-one with temporo-parietal lesions involving the TPJ and one with parietal lesions not involving the superior temporal gyrus - and concluded that the involvement of TPJ, but not of SPL, is crucial for the DD. The TPJ, including the underlying white matter, was also damaged in almost half of the patients in the Corbetta et al. (2005) study, whereas the IPS and FEF were spared in all patients. Finally, Snyder and Chatterjee (2006) reported that a difficulty with disengaging from an ipsilesional location to which attention has been directed exogenously can 


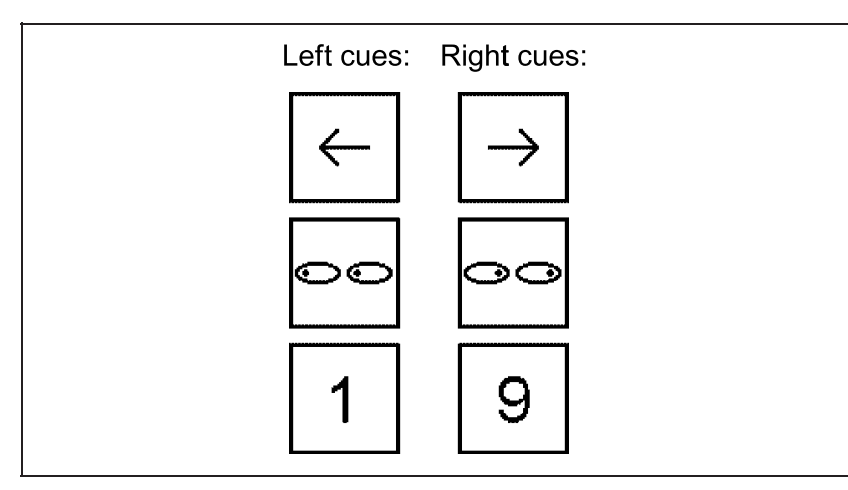

Figure 1. Central cues employed in the study.

also be found after lesions to more anterior regions and specifically to the inferior frontal gyrus.

As suggested by Klein (2004), the characteristics of the neglect syndrome can help us to understand the nature of ambiguous forms of attention orienting. The behavior of neglect patients in the case of central nonpredictive cueing can shed light on what characteristics of reflexive orienting relate more to exogenous versus endogenous attention mechanisms. In particular, we asked whether reflexive orienting in right braindamaged patients would show the asymmetries described for exogenous orienting after peripheral cueing (including the DD).

\section{EXPERIMENT 1: CUED DETECTION IN HEALTHY PARTICIPANTS}

The task was a variant of the spatial cueing paradigm introduced by Posner (1980). An irrelevant, nonpredictive cue was presented at fixation, followed by a target stimulus in one of two peripheral positions (left or right of fixation) that had to be detected by pressing a response key. The three types of cue (digit, arrow, or gazing eyes) were randomly intermixed. Stimulus onset asynchrony (SOA) was manipulated to map the time course of facilitation and inhibition for the different types of cue.

\section{Methods}

Twenty-six students of the University of Padua (14 females and 12 males) took part in the experiment. Their age ranged from 21 to 30 years (mean 23 years and 6 months). Five participants were left-handed. All had normal or corrected-to-normal vision.

The experiment was controlled by the E-Prime software (Schneider, Eschman, \& Zuccolotto, 2002) running on a Pentium III PC with a 17 -in. screen. A chin rest was used to prevent head movements. The distance between the monitor and the chin rest was $57 \mathrm{~cm}$. Three horizontally aligned boxes measuring $2.3^{\circ}$ of side were simultaneously presented in the central area of the screen (i.e., a left box, a central box, and a right box). The space between central and lateral boxes was $6.5^{\circ}$. The central box contained the fixation point (a cross measuring $0.3^{\circ}$ ). The cue (see Figure 1) was an arrow pointing leftward or rightward $\left(0.8^{\circ}\right.$ in height and $1^{\circ}$ in width) or a pair of eyes gazing leftward or rightward $\left(0.4^{\circ}\right.$ in height and $2.1^{\circ}$ in width) or the Arabic digits 1 or $9\left(0.9^{\circ}\right.$ in height and $0.5-0.7^{\circ}$ in width, corresponding, respectively, to a leftward and to a rightward cue). A cross measuring $1.3^{\circ} \times 1.3^{\circ}$ was used as a nondirectional, neutral cue. Thus, there were seven different cues, each presented for an equal number of trials during the experiment. All stimuli were black and were presented on a white background.

The three boxes were simultaneously presented in the central area of the screen and remained on until response (see Figure 2). After $1000 \mathrm{msec}$, the fixation point inside the central box disappeared and it was replaced by one of the possible cues (randomly selected but equiprobable) that remained on for $150 \mathrm{msec}$. After a variable SOA (i.e., 200, 350, 550, or $800 \mathrm{msec}$ ), a black circle (diameter $1^{\circ}$ ) appeared in one of the two lateral boxes and remained on until a response was executed or $2 \mathrm{sec}$ had elapsed from target onset. The cue was nonpredictive of target position (i.e., 50\% valid and $50 \%$ invalid trials). After response execution or the 2-sec delay, visual feedback was presented for $700 \mathrm{msec}$ (i.e., OK, anticipation, no response). A blank screen was finally presented for $500 \mathrm{msec}$ before starting the next trial.

Participants were instructed to keep their eyes on the central fixation point and to press the space bar with their dominant hand as fast as possible when the target appeared in one of the two lateral boxes. Participants performed a brief practice block (nine trials) before starting the task. The experiment comprised three blocks separated by two breaks. Each block comprised

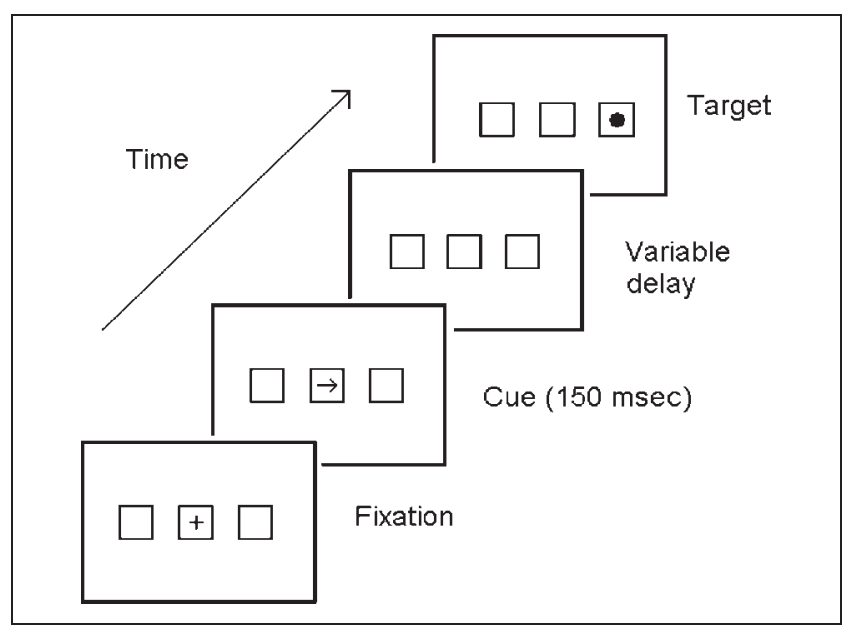

Figure 2. Example of a (valid) trial. 
Table 1. Mean RTs (msec) as a Function of SOA (msec) and Validity, Separately for Each Cue Category (Experiment 1)

\begin{tabular}{|c|c|c|c|c|c|c|c|c|}
\hline \multirow{2}{*}{$\frac{S O A}{\text { Validity }}$} & \multicolumn{2}{|c|}{200} & \multicolumn{2}{|c|}{350} & \multicolumn{2}{|c|}{550} & \multicolumn{2}{|c|}{800} \\
\hline & Invalid & Valid & Invalid & Valid & Invalid & Valid & Invalid & Valid \\
\hline Arrow & 331 & 316 & 312 & 296 & 301 & 291 & 315 & 314 \\
\hline Digit & 325 & 330 & 303 & 297 & 298 & 296 & 315 & 315 \\
\hline Gaze & 334 & 319 & 303 & 301 & 298 & 292 & 307 & 319 \\
\hline
\end{tabular}

133 trials, including 21 catch trials. The total number of trials was 399 .

\section{Results}

Missed responses were less than $0.1 \%$. False alarms rates for catch trials were $1.7 \%$ for arrow cues, $2.6 \%$ for digits, and $1.3 \%$ for gazing eyes. Mean RTs were calculated for each participant and experimental condition (i.e., cue type, SOA, and validity). Data trimming discarded RTs shorter than $100 \mathrm{msec}$ and longer than the mean plus three standard deviations ( $0.7 \%$ of the trials). The cross condition elicited slower RTs than the other cueing conditions (200 msec SOA: $334 \mathrm{msec} 350$ msec SOA: $310 \mathrm{msec} ; 50 \mathrm{msec}$ SOA: $310 \mathrm{msec} ; 800 \mathrm{msec}$ SOA: $321 \mathrm{msec}$ ) and was excluded from analyses.

The data were submitted to an omnibus repeated measures ANOVA with cue type (arrow, eye gaze, digit), SOA (200, 350, 550, $800 \mathrm{msec}$ ), and validity (valid trials vs. invalid trials) as factors. There were significant main effects of validity, $F(1,25)=9.68, p<.01$ (307 msec for valid trials vs. $312 \mathrm{msec}$ for invalid trials), and SOA, $F(3,75)=37.03, p<.001$. The two-way Validity $\times$ SOA interaction was also significant, $F(3,75)=4.27, p<.01$. The two-way Cue type $\times$ Validity interaction was significant, $F(2,50)=3.33, p<.05$, and also the three-way Cue type $\times$ Validity $\times$ SOA interaction was significant, $F(6,150)=2.22, p<.05$, suggesting differential effects for the different cue types. No other main effects or interactions were significant. Separate ANOVAs for each cue type were then performed (see data in Table 1).
For arrows, there were significant main effects of validity, $F(1,25)=10.55, p<.01$ (304 msec for valid trials vs. $315 \mathrm{msec}$ for invalid trials), and SOA, $F(3,75)=$ $24.09, p<.001$. The Validity $\times$ SOA interaction did not reach significance, $F(3,75)=2.29, p=.085$, but the RTs showed a trend toward a decreasing validity effect for the longer SOAs (see Figure 3A).

For digits, the only significant effect was that of SOA, $F(3,75)=20.82, p<.001$. Neither the main effect of validity nor its interaction with SOA was significant (both $F$ S $<1$; see Figure 3B).

For eye gaze, there was a significant main effect of SOA, $F(3,75)=21.69, p<.001$, whereas the main effect of validity was not significant, $F(1,25)=1.66, p=.21$. More importantly, the two-way Validity $\times$ SOA interaction was significant, $F(3,75)=6.4, p<.01$. Planned comparisons showed an advantage of valid over invalid trials at the 200-msec SOA [319 vs. $334 \mathrm{msec} ;(25)=$ $3.7, p<.005$, two tailed] and a late advantage of invalid over valid trials at the $800-\mathrm{msec}$ SOA [307 vs. $319 \mathrm{msec}$; $t(25)=-2.46, p<.05$, two tailed] (see Figure 3C).

\section{Discussion}

Cueing effects emerged as a function of cue type. There was a cueing effect for irrelevant, nonpredictive arrows and for eye gaze, consistently with previous studies that investigated these cues separately (e.g., Tipples, 2002; Hommel et al., 2001; Friesen \& Kingstone, 1998) or jointly (Ristic et al., 2002). Digits, instead, did not produce reflexive orienting (discussion of the lack of
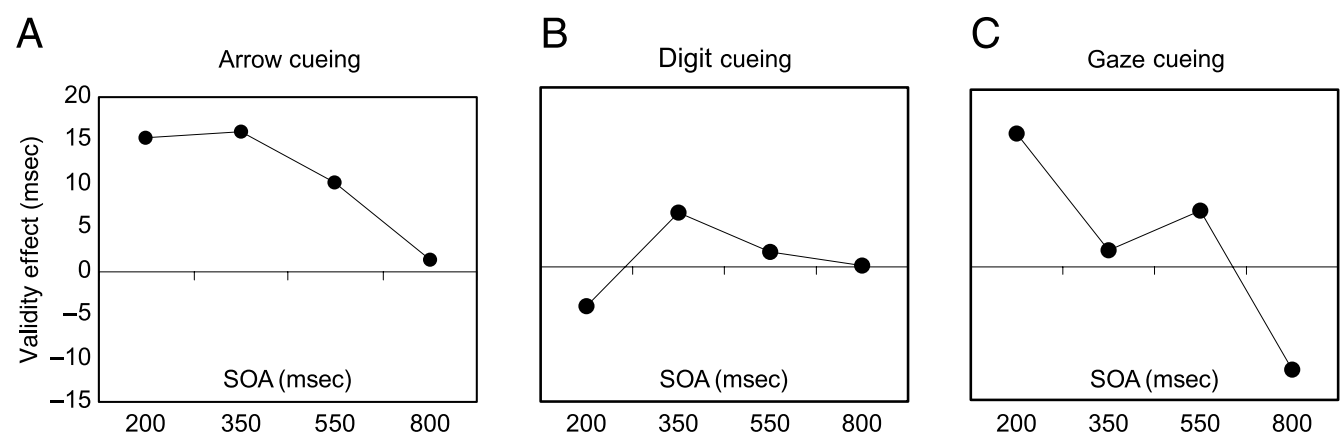

Figure 3. Validity effects (RTs for invalid minus RTs for valid trials) for healthy participants reported as a function of SOA separately for the three types of cue (panel A: arrow cues; panel B: digits cues; panel C: gaze cues). 
effect for digit cues is postponed to the General Discussion section). Cueing effects for both arrows and eye gaze emerged rapidly and tended to disappear at the longer SOAs.

For gaze cues, the early facilitatory effect turned into inhibition at the longer SOA. The majority of previous studies failed to find inhibitory effects after gaze cues (e.g., Friesen \& Kingstone, 1998, 2003). Inhibition at a long SOA (1000 msec) has been recently reported in a condition where a high number of catch trials was present (Okamoto-Barth \& Kawai, 2006). Interestingly, our experiment had a relatively large number of catch trials (16\%). Inhibition has also been found at very long SOAs (>2 sec; Frischen, Smilek, Eastwood, \& Tipper, 2007; but see McKee, Christie, \& Klein, 2007). However, these inhibitory phenomena are remarkably different from the classic IOR effect after peripheral cueing. Nonetheless, the present finding suggests that an inhibitory effect can be elicited under certain circumstances that are as yet not well understood.

\section{EXPERIMENT 2: CUED DETECTION IN RIGHT BRAIN-DAMAGED PATIENTS}

Experiment 2 was nearly identical to Experiment 1, but the participants were neurological patients with right hemisphere damage (with and without neglect). The experiment had two main aims. First, we asked whether neglect patients would show an imbalance in attentional orienting between contra- and ipsilesional hemifields (e.g., the DD) using central nonpredictive cueing. A larger validity effect in the contralesional hemifield after central nonpredictive cueing would indicate that the attentional mechanisms triggered by these cues are similar to those triggered by peripheral nonpredictive cues (i.e., they share an important characteristic with stimulus-driven orienting). In contrast, the absence of DD would indicate the recruitment of the spared mechanisms underlying voluntary orienting. Indeed, Losier and Klein (2001) found that the DD is inconsistent after central endogenous cueing.

The paradigm adopted for studying reflexive orienting presents two important advantages. First, it minimizes voluntary components because the cue is nonpredictive. Second, the presentation of the cue does not induce a spatial bias because it is centrally displayed; that is, if reflexive orienting can be elicited, it would be produced by the intrinsic directional meaning of the cue rather than by its spatial location. Note that the mere presence of lateral boxes in the display can increase the patients' asymmetry between ipsilesional and contralesional orienting (D'Erme, Robertson, Bartolomeo, Daniele, \& Gainotti, 1992).

Secondly, we asked whether patients would be differentially affected by the three cue types. Only one study employed gazing faces and arrows as central noninformative cues in a detection task in patients with neglect and extinction (Vuilleumier, 2002). Gaze direction oriented attention more effectively than arrow cues. The effect of numerical cues has never been investigated in studies of neglect patients.

\section{Methods \\ Participants}

Seventeen patients with right hemisphere brain lesion, confirmed by CT of MR scan, participated in the study (see Table 2). Patients were selected for the presence of a single right hemisphere lesion independently from intrahemispheric lesion site. They were admitted to a rehabilitation center to undergo motor rehabilitation for left hemiplegia/hemiparesis. All patients gave written informed consent to participate in the study. None of them had positive medical history of previous neurological disease or substance abuse. Patients with visual field deficits were not included in the study.

All patients were initially tested with the Mini-Mental State Examination (MMSE; Magni et al., 1996), and they were followed-up with a comprehensive neuropsychological battery (Mondini, Mapelli, Vestri, \& Bisiacchi, 2003). The conventional part of the Behavioural Inattention Test (BIT; Wilson, Cockburn, \& Halligan, 1987) was administered to investigate the presence of peripersonal neglect. It is a complex battery that includes different subtests: barrage, letter cancellation, star cancellation, bisection, coping, and drawing from memory tests. Right brain-damaged patients were assigned to the neglect group $(\mathrm{N}+)$ or to the group without neglect $(\mathrm{N}-)$ according to the score obtained in the conventional part of the BIT (range $=0-146$, cut-off $\leq 129 / 146$; see Table 2). Neglect had to be present in at least two subtests. Each patient performed also ecological tasks to assess the presence of neglect in the personal and extrapersonal (i.e., beyond reaching) hemispaces. Patients were all right-handed and they were affected by mild to severe motor deficits in the left hemibody. The $\mathrm{N}+$ group comprised nine patients with left hemispatial neglect, whereas the $\mathrm{N}$ - group comprised eight patients without left hemispatial neglect. The two groups $(\mathrm{N}+$ and $\mathrm{N}-$ ) did not differ in age, $F(1,15)=3.12, p=.098$, education, $F(1,15)=1.49, p=.24$, and time from lesion, $F(1,15)=0.61, p=.45$. The overall BIT score was instead significantly different, $F(1,15)=49.95, p<$ .001 , with a mean score higher for $\mathrm{N}-$ (143) than for $\mathrm{N}+$ (108).

Lesions were mapped for each patient using the MRIcro software (Rorden \& Brett, 2000) and were drawn manually on slices of a T1-weighted template MRI scan from the Montreal Neurological Institute. This template is oriented to match Talairach space (Talairach \& Tournoux, 1988) and is distributed with MRIcro. The matching with anatomical structures was done with the help of the BrainVoyager Brain Tutor (Brain Innovation, 
Table 2. Clinical and Demographic Data for Right Brain-Damaged Patients (Experiment 2)

\begin{tabular}{|c|c|c|c|c|c|c|c|c|c|c|c|c|c|c|c|c|c|}
\hline Group & $N+$ & $N+$ & $N+$ & $N+$ & $N+$ & $N+$ & $N+$ & $N+$ & $N+$ & $N-$ & $N-$ & $N-$ & $N-$ & $N-$ & $N-$ & $N-$ & $N-$ \\
\hline Patient & $\mathrm{RC}$ & GBR & $\mathrm{FB}$ & $\mathrm{AM}$ & $\mathrm{BA}$ & $\mathrm{PM}$ & TGA & PAM & AS & $\mathrm{EB}$ & $\mathrm{PZ}$ & DDC & DC & SM & SS & GB & LB \\
\hline Age (years) & 67 & 74 & 67 & 32 & 79 & 71 & 69 & 82 & 61 & 56 & 25 & 51 & 48 & 63 & 71 & 52 & 69 \\
\hline Education (years) & 3 & 5 & 5 & 13 & 5 & 5 & 5 & 5 & 13 & 18 & 13 & 8 & 5 & 13 & 3 & 13 & 2 \\
\hline Sex (male-female) & $\mathrm{F}$ & M & M & M & $\mathrm{F}$ & $\mathrm{F}$ & $\mathrm{F}$ & M & $\mathrm{F}$ & $\mathrm{F}$ & M & M & $\mathrm{F}$ & M & $\mathrm{F}$ & M & $\mathrm{F}$ \\
\hline Lesion site ${ }^{a}$ & Th, BG & $\mathrm{F}, \mathrm{P}, \mathrm{O}$ & $\mathrm{F}, \mathrm{P}$ & $\mathrm{F}, \mathrm{P}$ & $\mathrm{T}, \mathrm{BG}$ & $\mathrm{F}, \mathrm{P}$ & $\mathrm{F}, \mathrm{P}$ & $\mathrm{F}, \mathrm{P}$ & $\mathrm{T}, \mathrm{P}, \mathrm{Th}$ & $\mathrm{F}$ & IC & $B G$ & BG & Parav & $\mathrm{F}, \mathrm{T}, \mathrm{P}$ & IC & IC \\
\hline Aethiology $^{\mathrm{b}}$ & $\mathrm{H}$ & I & $\mathrm{H}^{\mathrm{c}}$ & $\mathrm{H}^{\mathrm{c}}$ & I & I & $\mathrm{H}$ & I & I & $\mathrm{H}^{\mathrm{c}}$ & I & $\mathrm{H}$ & $\mathrm{H}$ & I & I & I & $\mathrm{H}$ \\
\hline MMSE & 23 & 21 & 24 & 23 & 24 & 20 & 21 & 25 & 28 & 30 & 30 & 27 & 23 & 29 & 27 & 29 & 22 \\
\hline Time since lesion ${ }^{\mathrm{d}}$ & 53 & 42 & 348 & 38 & 30 & 29 & 123 & 36 & 40 & 87 & 65 & 61 & 54 & 33 & 38 & 41 & 45 \\
\hline $\begin{array}{l}\text { Visual extinction } \\
(+, \text { if present })\end{array}$ & + & + & + & - & - & + & + & - & + & - & - & - & - & - & - & - & - \\
\hline BIT total & 123 & 79 & 124 & 103 & 104 & 104 & 114 & 112 & 106 & 140 & 146 & 145 & 133 & 144 & 144 & 145 & 145 \\
\hline \multicolumn{18}{|l|}{ Bit subtests } \\
\hline $\begin{array}{l}\text { Line cancellation } \\
\quad(18-18)^{\mathrm{e}}\end{array}$ & $18-18$ & $2-18$ & $18-18$ & $18-18$ & $18-17$ & $18-18$ & $18-18$ & $18-18$ & $18-18$ & $18-18$ & $18-18$ & $18-18$ & $18-18$ & $18-18$ & $18-18$ & $18-18$ & $18-18$ \\
\hline $\begin{array}{l}\text { Letter cancellation } \\
\quad(20-20)^{\mathrm{e}}\end{array}$ & 20-18 & $14-15$ & $14-20$ & $5-17$ & $13-12$ & $4-16$ & 19-19 & $16-18$ & $12-15$ & 19-20 & $20-20$ & $20-20$ & $16-17$ & $20-18$ & 19-20 & $20-20$ & 20-20 \\
\hline $\begin{array}{l}\text { Star cancellation } \\
\qquad(27-27)^{\mathrm{e}}\end{array}$ & $12-22$ & $0-25$ & $17-25$ & $10-24$ & $9-25$ & 18-21 & $8-24$ & $21-15$ & $9-25$ & $25-24$ & $27-27$ & $26-27$ & $23-26$ & $27-27$ & $27-26$ & $27-26$ & $27-27$ \\
\hline Copying $(4)^{\mathrm{f}}$ & 3 & 2 & 2 & 3 & 2 & 4 & 2 & 3 & 3 & 4 & 4 & 4 & 4 & 4 & 4 & 4 & 3 \\
\hline Line bisection $(9)^{\mathrm{g}}$ & 9 & 1 & 9 & 6 & 5 & 3 & 6 & 1 & 5 & 9 & 9 & 9 & 9 & 9 & 9 & 9 & 9 \\
\hline Drawing $(3)^{\mathrm{f}}$ & 3 & 2 & 1 & 2 & 3 & 2 & 0 & 2 & 1 & 3 & 3 & 3 & 2 & 3 & 3 & 3 & 3 \\
\hline
\end{tabular}

${ }^{a}$ Confirmed by neuroradiological report. Th $=$ thalamus; $\mathrm{T}=$ temporal; $\mathrm{P}=$ parietal; $\mathrm{BG}=$ basal ganglia; $\mathrm{F}=$ frontal; $\mathrm{O}=$ occipital; $\mathrm{IC}=$ internal capsule; Parav $=$ paraventricular.

${ }^{\mathrm{b}} \mathrm{H}=$ hemorrhagic, $\mathrm{I}=$ ischemic.

${ }^{\mathrm{c}}$ Neurosurgery.

${ }^{\mathrm{d}}$ Days

BIT subtests: maximum scores are shown in brackets.

${ }^{\mathrm{e}}$ The two numbers refer to the scores (items marked) in each cancellation task for left and right hemispace, respectively.

${ }^{\mathrm{f}}$ One point is given for each task (four copying and three drawing tasks) if performance does not reveal important asymmetries.

${ }^{g}$ Bisection of each of the three lines in the subtest is scored from 0 to 3 according to the accuracy of performance. 
Maastricht, The Netherlands). Because the two patient groups differed in sample size, we used proportional values for the MRIcro subtraction analysis.

\section{Procedure}

The experiment was run on a portable PC with a 14-in. screen. The patient's trunk was aligned with the center of the screen. Distance between the patient's eyes and the screen was approximately $55 \mathrm{~cm}$. The experimental procedure was nearly identical to Experiment 1 but there were only three SOAs (200, 500, and $1000 \mathrm{msec})$. The target was presented until response or until a 4000-msec deadline. Auditory feedback was provided after response execution (i.e., a high-pitch tone for correct responses or a low-pitch tone for responses to catch trials). As in Experiment 1, the central cues were digits, arrows, and gazing eyes. The neutral (cross) condition was not used. The side of each box was $16 \mathrm{~mm}$, and the space between central and lateral boxes was $46 \mathrm{~mm}$. The diameter of the black circle used as target was $8 \mathrm{~mm}$. The start of each trial was controlled by the experimenter using an external device (mouse). For eight neglect patients and for three control patients, ocular movements were controlled on-line, and affected trials were removed. Patients were allowed to take short rests whenever they needed. The experiment was run in two consecutive days at the same daytime except for patient BA whose two sessions were separated by a week because of medical complications (i.e., low blood pressure). Patients were instructed to fixate the central box and to respond to the target as quickly as possible by pressing the response key using their nonplegic right hand. Twelve practice trials were performed before starting the experiment and were repeated if necessary. Each block consisted of 90 trials, including 18 catch trials, and lasted about $10 \mathrm{~min}$. Each patient performed a total of six blocks, three in each of the two testing days, for a total of 540 trials, with the exception of patients TGA and SS, who performed five blocks (i.e., 450 trials).

\section{Results}

\section{Behavioral Data}

Missed responses (i.e., responses not executed within $4 \mathrm{sec}$ after target onset) were on average $0.6 \%$ (range $=$ 0-3\%). False alarms rates for catch trials were 1.4\% for arrow and digit cues and $0.5 \%$ for eye gaze cues. Data trimming was the same as in Experiment 1, and $0.5 \%$ of trials were discarded. An omnibus mixed ANOVA was then performed on RTs with cue type (arrow, digit, eye gaze), validity (valid vs. invalid), hemifield (left vs. right), and SOA (200, 500, $1000 \mathrm{msec}$ ) as withinparticipants factors and with group $(\mathrm{N}+$ vs. $\mathrm{N}-$ ) as between-participants factor.

The ANOVA showed a main effect of hemifield, $F(1$, $15)=39.5, p<.001$ (right $507 \mathrm{msec}$ vs. left $638 \mathrm{msec}$ ), and validity, $F(1,15)=10.94, p<.01$ (valid $560 \mathrm{msec}$ vs. invalid $585 \mathrm{msec}$ ). A large number of two- and threeway interactions were significant: Hemifield $\times$ Group, $F(1,15)=16.68, p<.01$; Cue type $\times$ Validity, $F(2,30)=$ $8.29, p<.01$; Cue type $\times$ Validity $\times$ Group, $F(2,30)=$ $4.7, p<.05$, suggesting that cueing effects differ for $\mathrm{N}+$ and $\mathrm{N}-$; Cue type $\times$ Validity $\times$ Hemifield, $F(2,30)=$ $4.91, p<.05$, suggesting the presence of differential cueing effects for the three types of cue in the left (contralesional) versus right (ipsilesional) hemifields. No other main effects or interactions were significant. Note that many of the significant interactions are likely derived from the four-way Cue type $\times$ Validity $\times$ Hemifield $\times$ Group interaction that did not reach significance, $F(2,30)=$ $2.55, p=.095$. In the following analyses, we will examine each cue type separately and by doing so shed some light on the nature of these interactions.

A series of separate ANOVAs using validity (valid vs. invalid) and hemifield (left vs. right) as factors was subsequently performed to investigate the differential cueing effect for the three types of cue and for the two groups of patients (see Figure 4 for $\mathrm{N}-$ and Figure 5 for $\mathrm{N}+$; Table 3 reports mean RTs for each condition). Note that the effectiveness of the cue in orienting attention is indexed by a significant validity effect, whereas the
Figure 4. Validity effects (RTs for invalid minus RTs for valid trials) for $\mathrm{N}-$ patients reported as a function of SOA and hemispace separately for the three types of cue (panel A: arrow cues; panel B: digit cues; panel C: gaze cues). Filled circles represent left targets whereas empty circles represent right targets.

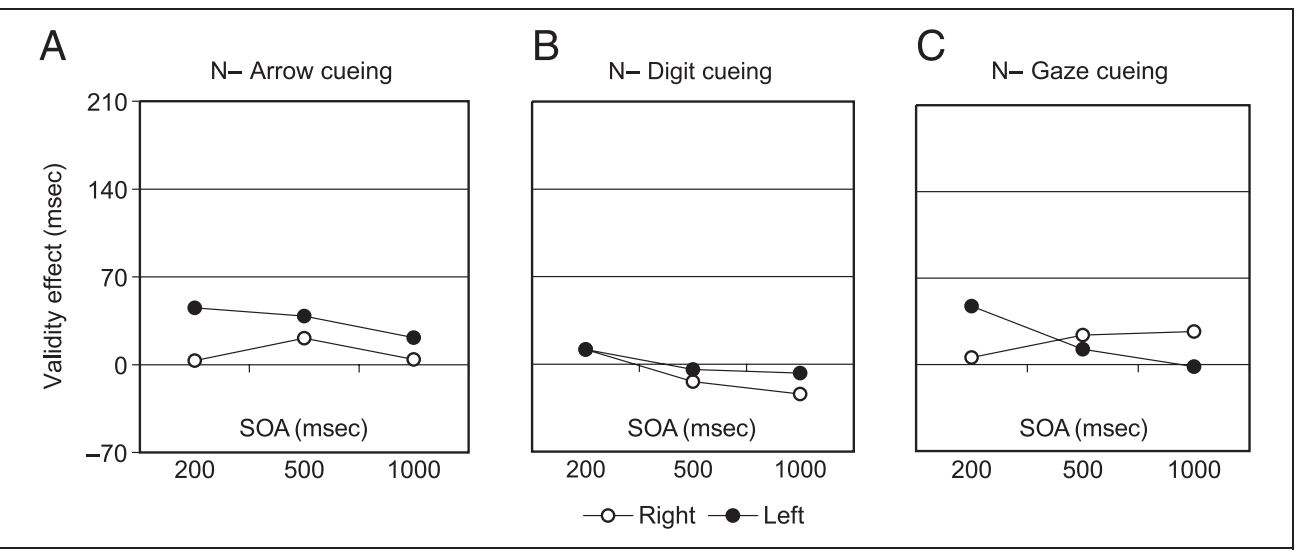


Figure 5. Validity effects (RTs for invalid minus RTs for valid trials) for $\mathrm{N}+$ patients reported as a function of SOA and hemispace separately for the three types of cue (panel A: arrow cues; panel B: digit cues; panel C: gaze cues). Filled squares represent left targets whereas empty squares represent right targets.

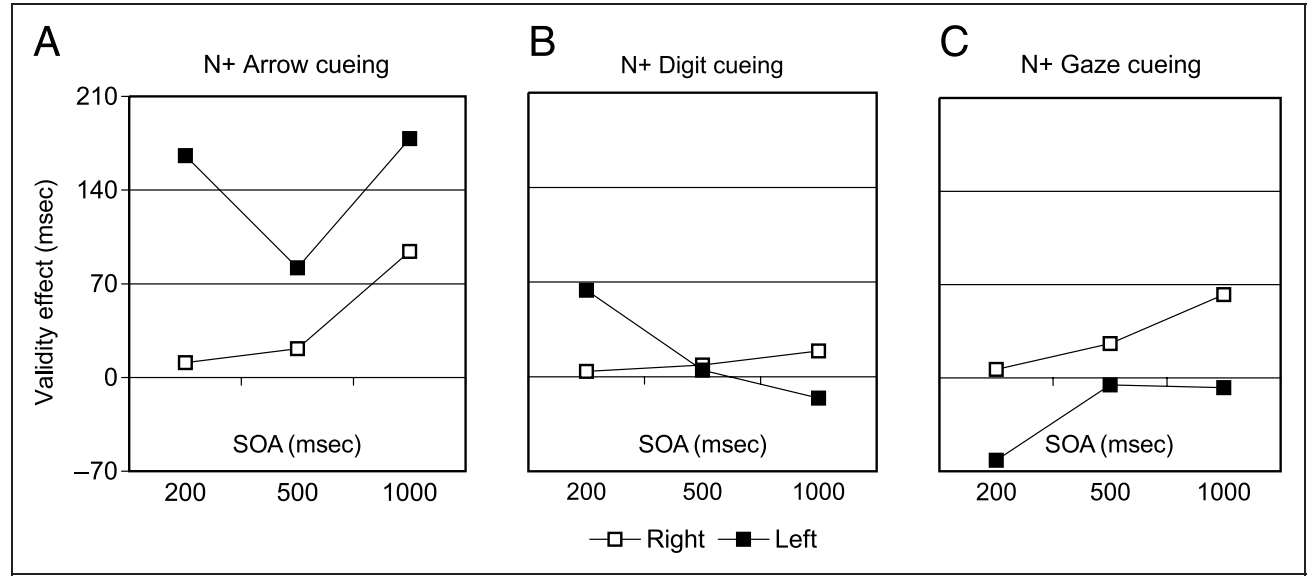

presence of a DD is reflected in a significant Validity $\times$ Hemifield interaction (Losier \& Klein, 2001).

For arrows, the main effects of validity were significant in $\mathrm{N}+, F(1,8)=11.77, p<.01$ (valid trials $614 \mathrm{msec}$, invalid trials $706 \mathrm{msec}$ ), and in $\mathrm{N}-, F(1,7)=22.24, p<$ .01 (valid trials $464 \mathrm{msec}$, invalid trials $486 \mathrm{msec}$ ). Also the main effect of hemifield was significant both in $\mathrm{N}+$, $F(1,8)=24.53, p<.01$ (left targets $755 \mathrm{msec}$ vs. right targets $564 \mathrm{msec}$ ), and in $\mathrm{N}-, F(1,7)=13.21, p<.01$ (left targets $495 \mathrm{msec}$ vs. right targets $455 \mathrm{msec}$ ). The Hemifield $\times$ Validity interaction was significant for $\mathrm{N}+$ only, $F(1,8)=5.59, p<.05$, indexing larger cueing effects for targets appearing in the left (invalid trials $826 \mathrm{msec}$ vs. valid trials $684 \mathrm{msec}$ ) with respect to the right hemifield (invalid trials $585 \mathrm{msec}$ vs. valid trials $543 \mathrm{msec}$ ) and signaling a significant DD in the $\mathrm{N}+$ but not in the $\mathrm{N}-$ group.

For digits, the main effect of validity was neither significant in $\mathrm{N}+, F(1,8)=1.07, p=.33$, nor in $\mathrm{N}-, F<1$. The main effect of hemifield was significant both in $\mathrm{N}+, F(1,8)=23.42, p<.01$ (left targets $750 \mathrm{msec}$ vs. right targets $550 \mathrm{msec}$ ), and in $\mathrm{N}-, F(1,7)=7.9, p<.05$ (left targets $482 \mathrm{msec}$ vs. right targets $453 \mathrm{msec}$ ). The Hemifield $\times$ Validity interaction was neither significant in $\mathrm{N}+, F<1$, nor in $\mathrm{N}-, F(1,7)=1.08, p=.34$.

For eye gaze, the main effect of validity was not significant in $\mathrm{N}+, F<1$, whereas it was significant in $\mathrm{N}-$, $F(1,7)=16.08, p<.01$ (valid trials $462 \mathrm{msec}$, invalid trials $481 \mathrm{msec}$ ). The main effect of hemifield was significant both in $\mathrm{N}+, F(1,8)=20.57, p<.01$ (left targets $794 \mathrm{msec}$ vs. right targets $561 \mathrm{msec}$ ), and in $\mathrm{N}-, F(1$, 7 ) $=20.28, p<.01$ (left targets $503 \mathrm{msec}$ vs. right targets $440 \mathrm{msec}$ ). The Hemifield $\times$ Validity interaction was not significant in $\mathrm{N}-, F<1$, whereas in $\mathrm{N}+$ the data showed a nonsignificant trend toward a validity effect for the right hemifield ( $577 \mathrm{msec}$ for invalid vs. $545 \mathrm{msec}$ for valid trials; $F(1,8)=3.65, p=.092$ ).

The initial findings can be summarized as follows: (i) arrows effectively oriented attention in both $\mathrm{N}+$ and $\mathrm{N}-$ patients; (ii) eye-gaze effects were reliable in $\mathrm{N}-$ but not in $\mathrm{N}+$; and (iii) digit cueing was not effective in either group of patients. Moreover, in the case of arrow cueing, the $\mathrm{N}+$ patients showed an asymmetric pattern of orienting (i.e., a larger validity effect in the contralesional

Table 3. Mean RTs (msec) as a Function of SOA (msec), Hemifield, and Validity, Separately for Each Cue Category and Experimental Group

\begin{tabular}{|c|c|c|c|c|c|c|c|c|c|c|c|c|c|}
\hline \multirow{3}{*}{$\begin{array}{l}\text { SOA } \\
\text { Hemifield } \\
\text { Validity }\end{array}$} & & \multicolumn{4}{|c|}{200} & \multicolumn{4}{|c|}{500} & \multicolumn{4}{|c|}{1000} \\
\hline & & \multicolumn{2}{|c|}{ Left } & \multicolumn{2}{|c|}{ Right } & \multicolumn{2}{|c|}{ Left } & \multicolumn{2}{|c|}{ Right } & \multicolumn{2}{|c|}{ Left } & \multicolumn{2}{|c|}{ Right } \\
\hline & & Invalid & Valid & Invalid & Valid & Invalid & Valid & Invalid & Valid & Invalid & Valid & Invalid & Valid \\
\hline Cue type & Group & & & & & & & & & & & & \\
\hline Arrow & $\mathrm{N}-$ & 518 & 472 & 473 & 470 & 518 & 479 & 452 & 431 & 503 & 481 & 453 & 449 \\
\hline Digit & $\mathrm{N}-$ & 504 & 492 & 468 & 456 & 475 & 480 & 438 & 452 & 467 & 474 & 441 & 465 \\
\hline Gaze & $\mathrm{N}-$ & 558 & 511 & 454 & 449 & 496 & 484 & 441 & 417 & 483 & 484 & 451 & 425 \\
\hline Arrow & $\mathrm{N}+$ & 821 & 656 & 565 & 554 & 811 & 729 & 563 & 541 & 847 & 668 & 628 & 534 \\
\hline Digit & $\mathrm{N}+$ & 746 & 682 & 567 & 563 & 822 & 817 & 533 & 524 & 708 & 724 & 567 & 548 \\
\hline Gaze & $\mathrm{N}+$ & 759 & 821 & 548 & 542 & 831 & 836 & 582 & 556 & 754 & 761 & 599 & 537 \\
\hline
\end{tabular}


hemifield) that suggests the presence of DD. To further investigate this latter issue, we performed additional analyses to establish whether the Validity $\times$ Hemifield interaction for arrow cues was specific to short SOAs, as typically found in the case of peripheral noninformative cues (Losier \& Klein, 2001). Indeed, the interaction was significant at the shortest SOA only, $F(1,8)=7.75$, $p<.05$ (left valid $=656 \mathrm{msec}$; right valid $=554 \mathrm{msec}$; left invalid $=821 \mathrm{msec}$; right invalid $=565 \mathrm{msec}$ ). This result indicates that the DD emerges after central nonpredictive arrow cueing exactly in the same conditions where it is more consistently found after peripheral noninformative cueing, that is, after a short SOA and in the presence of hemispatial neglect (for a review, see Losier \& Klein, 2001).

We then quantified the DD by subtracting RTs to valid trials from RTs to invalid trials, separately for left and right targets (e.g., Losier \& Klein, 2001). The difference for right targets was then subtracted from the difference for left targets at the shortest (i.e., $200 \mathrm{msec}$ ) SOA (i.e., [left invalid - left valid] - [right invalid - right valid]). Figure 6 shows the DD as a function of cue type and group. A one-sample $t$ test confirmed that the size of DD at the shortest SOA for arrow cueing in N+ (mean $155 \mathrm{msec}$, $S D=167 \mathrm{msec}, S E M=56 \mathrm{msec}$ ) was significantly different from zero, $t(8)=2.78, p<.05$ (two-tailed).

Because the presence of the DD was reliable in neglect patients only, we investigated the role of the presence and the degree of left hemiattention in modulating the deficit. We hypothesized that neglect modulates the DD in a continuous rather than in a discrete (dichotomous) manner. Thus, we performed a series of regression analyses using BIT score as predictor for the magnitude of the DD. The BIT score reliably predicted the magnitude of the DD induced by arrow cueing at the shortest SOA across the whole sample of 17 right brain-damaged patients, $B=-3.39, R^{2}=.26, F(1,15)=5.14, p<.05$ (see Figure 7). Inspection of the data, however, revealed that the patient displaying the most severe neglect (GBR; BIT score $=79$; all other patients performed above 100) presented with a peculiar pattern: At the longer SOA (1000 msec), he dramatically slowed his responses for invalid trials after rightward arrow cueing as if he was persisting in a rightward search $(891 \mathrm{msec}$ for the first SOA vs. $938 \mathrm{msec}$ for the second vs. $1557 \mathrm{msec}$ for the third). Excluding his data from the regression analysis (as outlier with respect to all other patients) resulted in a better fit, $B=-4.85, R^{2}=.35, F(1,14)=7.66, p<.05$.

Processing of validly cued targets is know to be slower in the contralesional hemifield than in the ipsilesional one (e.g., Siéroff et al., 2007; Losier \& Klein, 2001). To investigate this phenomenon, we performed a separate ANOVA on valid trials with cue type (arrow, eye gaze, digit), hemifield (left vs. right), and group ( $\mathrm{N}-$ vs. $\mathrm{N}+$ ) as factors. The main effect of hemifield was significant, $F(1,15)=41.3, p<.001$. Also the Hemifield $\times$ Group interaction was significant, $F(1,15)=18.99, p<.01$. The difference between left and right valid trials was much larger for the $\mathrm{N}+$ group [744 vs. $544 \mathrm{msec}, t(8)=5.9$, $p<.001$ ], although it was still significant for the $\mathrm{N}-$ group [ 484 vs. $446 \mathrm{msec}, t(7)=3.9, p<.01]$. The difference between $\mathrm{N}+$ and $\mathrm{N}-$ was significant for left valid trials, $F(1,15)=15.04, p<.01$, but it did not reach significance for right valid trials, $F(1,15)=3.88, p=$ .068. The Cue type $\times$ Hemifield interaction was also significant, $F(2,30)=5.94, p<.01$, indicating slower responses for gaze-cued right valid trials. Finally, the difference between left valid and right valid trials was predicted by the BIT score in a regression analysis that included all right brain-damaged patients, $B=-4.57$, $R^{2}=.72, F(1,15)=38.06, p<.001$.

\section{Lesion Data}

We performed an anatomical analysis of the patients' lesions to examine the involvement of the VFC-TPJ
Figure 6. Mean DD (validity effect for left targets minus validity effect for right targets) at the 200-msec SOA for $\mathrm{N}-$ and $\mathrm{N}+$ patients as a function of cue type.

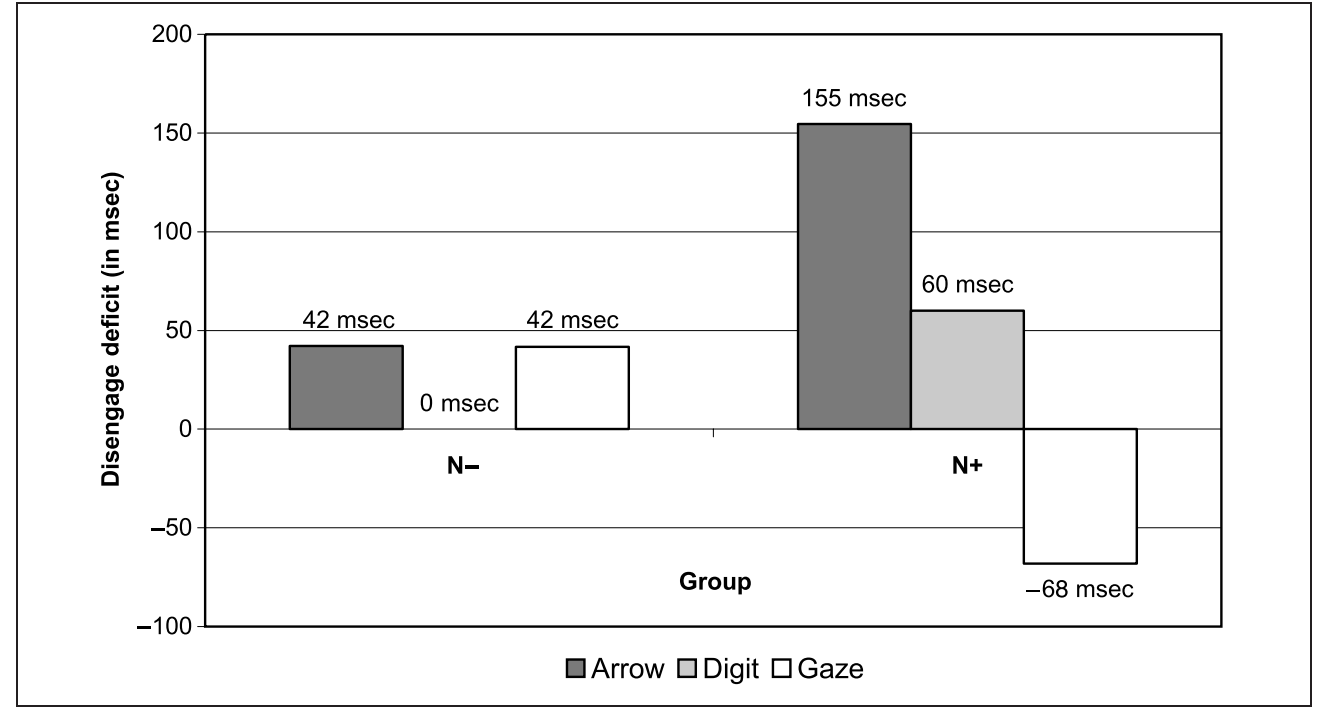


Figure 7. Mean DD for arrow-cued targets at the 200-msec SOA as a function of the BIT score in all right brain-damaged patients (circles: N+ patients; squares: $\mathrm{N}$ - patients). The regression line shown in the graph was fitted excluding the data point corresponding to patient GBR (empty circle).

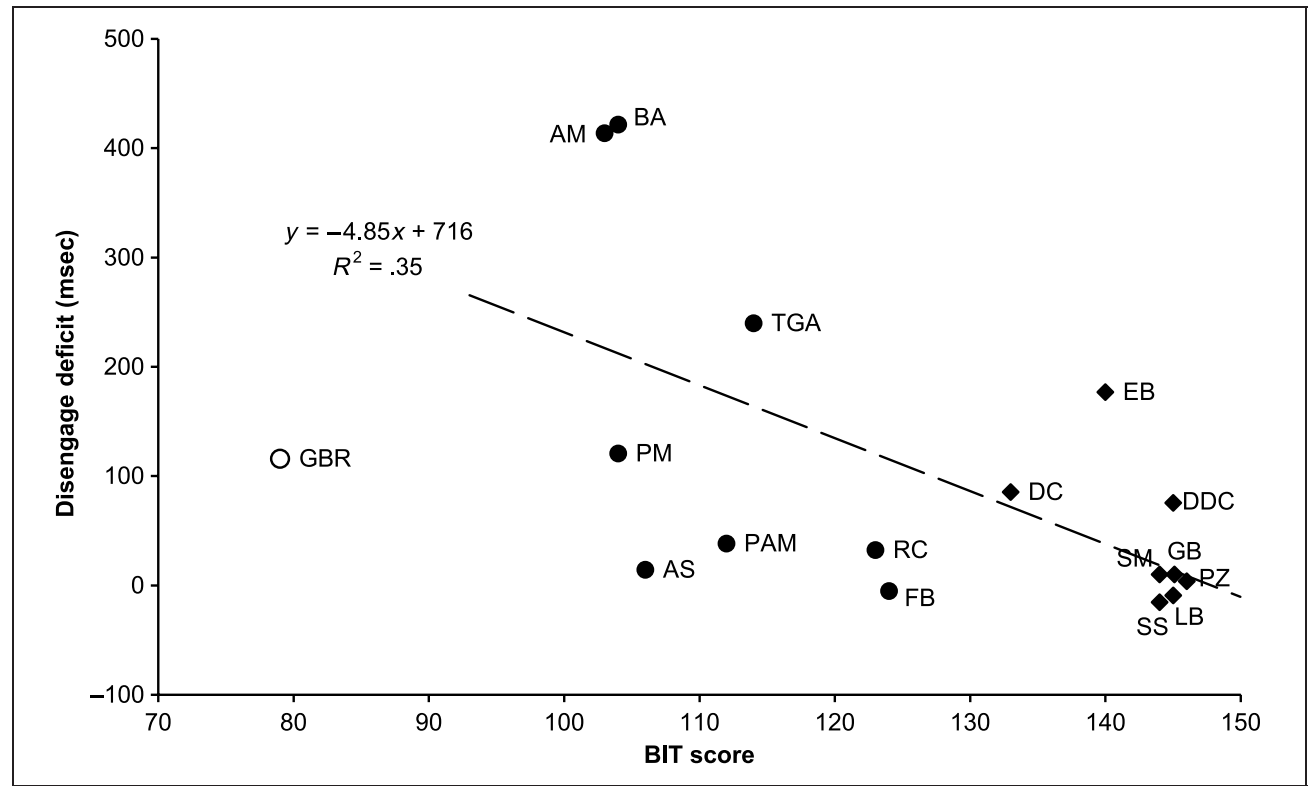

network and its association to the DD for arrow cues. Note that our study did not aim at investigating the neuroanatomy of neglect, which is still a highly controversial issue (e.g., Bartolomeo, Thiebaut de Schotten, \& Doricchi, 2007; Mort et al., 2003; Karnath, Ferber, \& Himmelbach, 2001).

Lesions were reconstructed for each patient (see Methods section of Experiment 2) on axial brain slices into a standard T1 MRI template (Rorden \& Brett, 2000).
Figure 8 illustrates conventional lesion density plots for the 14 patients whose anatomical scans were available. The number of overlapping lesions is coded with increasing frequencies from violet ( $n=1$ patient) to red ( $n=$ all patients in the respective group). The lesions for both $\mathrm{N}+$ (eight patients; see Figure 8A) and $\mathrm{N}-$ (six patients; see Figure 8B) involved several different brain regions typically associated with motor impairments. For the $\mathrm{N}+$ group, the overlap involved fronto-

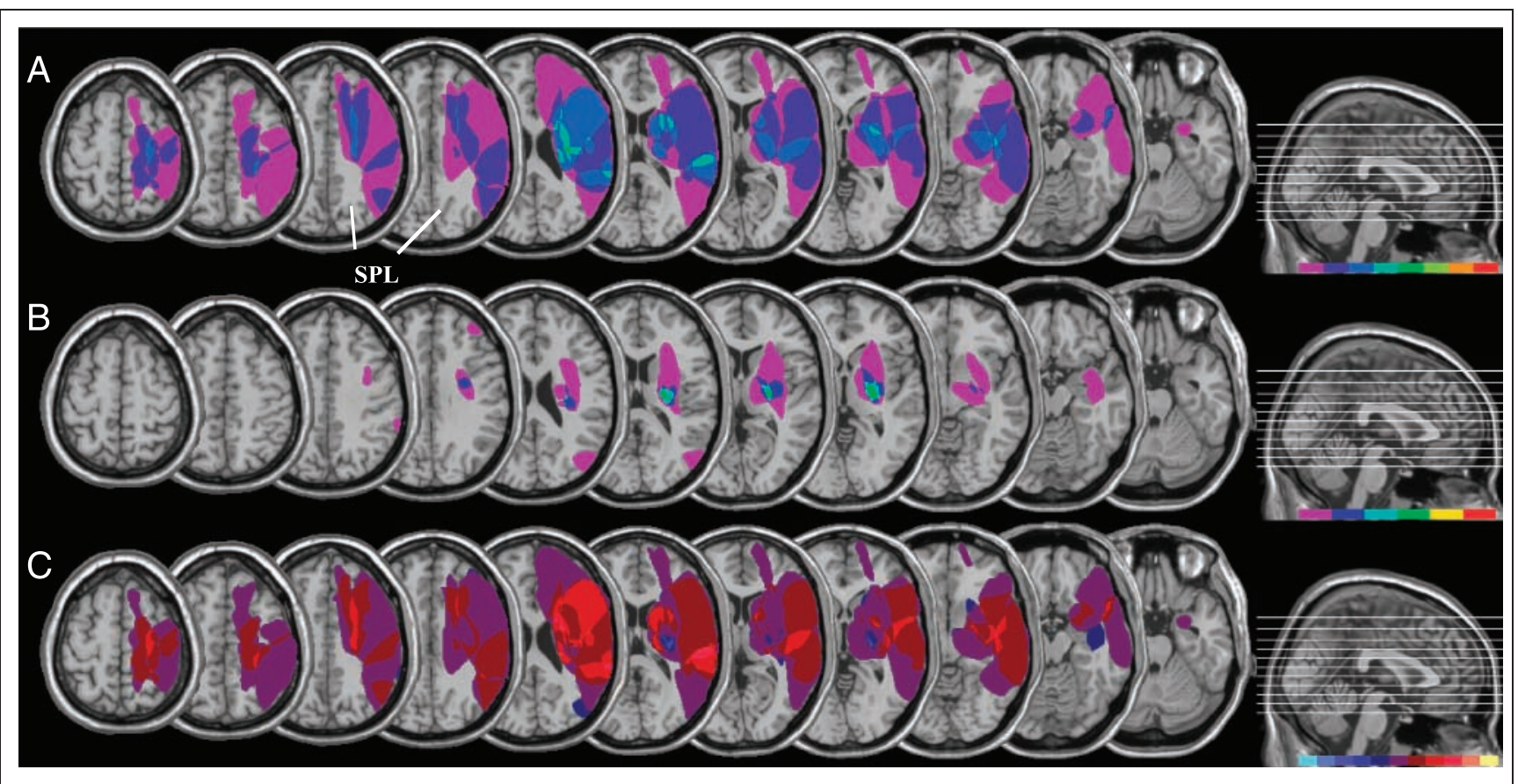

Figure 8. Lesion reconstruction for the $\mathrm{N}+$ patients (A) and $\mathrm{N}-$ patients (B) using MRIcro templates (Rorden \& Brett, 2000). Slices that correspond to Talairach coordinates $Z 60,50,40,32,24,16,8,0,-8,-16$, and -24 are shown. The percentage of overlapping lesions of the $\mathrm{N}+$ group after subtraction of the $\mathrm{N}-$ group is illustrated in panel $\mathrm{C}$ by five different colors coding increasing frequencies from dark red to white yellow. Colors from dark blue to light blue indicate regions damaged more frequently in the $\mathrm{N}-$ than in the $\mathrm{N}+$ group. 
temporo-parietal as well as subcortical areas, as found in previous studies of neglect (Bartolomeo et al., 2007; Mort et al., 2003; Karnath et al., 2001; Mesulam, 1999). Moreover, most of the SPL was spared, as consistently shown by previous studies that investigated the presence of the DD (Snyder \& Chatterjee, 2006; Corbetta et al., 2005; Friedrich et al., 1998). For N- patients, the maximum overlap involved the posterior putamen and the posterior part of the internal capsule. We then subtracted the superimposed lesions of $\mathrm{N}-$ from those of $\mathrm{N}+$ to obtain an overlay plot (Figure $8 \mathrm{C}$ ). Half of the $\mathrm{N}+$ patients had damage to the TPJ component of the VFC-TPJ network. Indeed, the cortical area most often damaged in the $\mathrm{N}+$ group was the superior temporal gyrus. Some patients had subcortical lesions only, but it is worth noting that both thalamus and BG have direct anatomical connections with the superior temporal gyrus and that lesions to the deep white matter connections might play an important role in the occurrence of neglect (for a review, see Bartolomeo et al., 2007).

Lesion volume was also calculated for each patient. The $\mathrm{N}+$ group had larger lesions than the $\mathrm{N}-$ group, $F(1,12)=5.48, p<.05$ (75 vs. $11 \mathrm{cc}$ ). We then tested across all 14 patients (i.e., merging $\mathrm{N}+$ and $\mathrm{N}-$ ) whether lesion size was predictive of the BIT score or, more importantly, of DD magnitude. Lesion size significantly predicted the BIT score, $B=-0.21, R^{2}=.33, F(1,12)=$ $5.89, p<.05$; that is, larger lesion volumes were associated with lower BIT scores (hence more severe neglect). In contrast, lesion volume did not predict the magnitude of the DD, $B=-0.14, R^{2}=.003, F(1,12)=$ $.037, p=.85$.

Finally, we asked whether damage to the STS (which is known to mediate the processing of gaze direction; for a review, see Frischen, Bayliss, et al., 2007) in some of the $\mathrm{N}+$ patients might account for the absence of gaze cueing effect in the contralesional hemifield. Four $\mathrm{N}+$ patients (AS, GBR, PM, and PAM) presented with damage that extended into the STS. We, therefore, compared the validity effect after gaze cues (collapsed across SOAs) for these four patients versus the other four $\mathrm{N}+$ patients that had no STS damage. The difference was nonsignificant, both in the right, $F(1,6)=0.32, p=.59$ (32 msec for the patients without STS involvement vs. $17 \mathrm{msec}$ for patients with STS involvement), and in the left hemifield, $F(1,6)=0.01, p=.95(-24 \mathrm{msec}$ for the patients without STS involvement vs. -29 msec for patients with STS involvement).

\section{Discussion}

The aim of Experiment 2 was to study, in right braindamaged patients, the attentional mechanisms engaged by a Posner-like task with central nonpredictive cues that have a directional meaning. We found that attention orienting was modulated by cue category and by the presence of neglect. As for healthy participants, arrows effectively oriented visuospatial attention in both Nand $\mathrm{N}+$, whereas digits did not. The orienting effect of gaze cues was consistent in $\mathrm{N}-$ only.

Experiment 2 allowed us to specifically assess the presence of the DD and to quantify its magnitude. The DD was observed only in the $\mathrm{N}+$ group when the target was cued by an arrow, selectively for the shortest SOA. Losier and Klein (2001) found in their meta-analysis that the DD is inconsistent after central endogenous cueing, but it should be noted that endogenous and reflexive orienting were confounded in the studies that employed arrows as central predictive cues (Corbetta et al., 2005; Làdavas, Carletti, et al., 1994; Nagel-Leiby et al., 1990; Posner et al., 1984). Our results show that the DD can be observed even when the cue is nonpredictive but centrally presented. Thus, reflexive orienting after central nonpredictive arrows presents with some features that were previously thought to characterize stimulus-driven attentional control.

A comparison of the DD from arrow cues with that obtained from peripheral cues, however, suggests that the former has smaller magnitude. We selected from Losier and Klein's (2001) meta-analysis the studies that had separate data for $\mathrm{N}+$ or $\mathrm{N}-$ (i.e., excluding studies where data from $\mathrm{N}+$ and $\mathrm{N}-$ were collapsed). Across SOAs, a DD of $234 \mathrm{msec}$ was found for $\mathrm{N}+$ after peripheral noninformative cueing (Farah et al., 1989), and a DD of $246 \mathrm{msec}$ was found when peripheral cueing was informative (D'Erme et al., 1992). For N-, peripheral informative cueing produced a mean DD of $27 \mathrm{msec}$ (Egly, Driver, \& Rafal, 1994), and a study combining peripheral informative and noninformative cueing reported a DD of 14 msec (Friedrich et al., 1998). A recent study of Siéroff et al. (2007) reported a mean DD after peripheral noninformative cueing of $218 \mathrm{msec}(\mathrm{N}+)$ versus $32 \mathrm{msec}(\mathrm{N}-)$ for a 100-msec SOA. The mean DD in our study for arrow cueing at the shortest SOA was $42 \mathrm{msec}$ for $\mathrm{N}-$ and $155 \mathrm{msec}$ for $\mathrm{N}+$. It is, thus, possible that the DD after central nonpredictive arrows is quantitatively reduced compared with the DD elicited by peripheral cues. However, caution in interpreting this comparisons is mandatory because, as we have shown, the size of the DD correlates with the severity of neglect.

Our finding that the DD can be elicited by a central nonpredictive cue shows that the deficit cannot be accounted for by an unspecific attraction for stimuli appearing in the ipsilesional hemifield. In the case of left invalid trials, neither the cue nor the target appeared in the ipsilesional hemifield. The hypothesis that the DD is simply related to the abrupt onset of a cue attracting attention to the ipsilesional hemifield is also inconsistent with the findings of Ptak and Schnider (2006), who showed that ipsilesional attraction of attention is influenced by behavioral saliency. It is worth noting that neglect patients' asymmetry in attentional orienting cannot be fully explained by either contralesional hypoattention or ipsilesional hyperattention alone (Bartolomeo \& Chokron, 1999). 
Losier and Klein (2001) concluded that the DD is more consistent in the presence of neglect. Our study confirmed this finding and showed that the magnitude of the DD for arrow cueing at the shortest SOA (200 msec) is predicted by the BIT score across the entire sample of right brain-damaged patients. To our knowledge, there are four other studies that compared neglect severity with the size of the DD. Morrow and Ratcliff (1988) reported that the DD after peripheral predictive cueing (75\% of valid trials) correlated with standard tests for neglect assessment. In contrast, two other studies that used peripheral cueing (Siéroff et al., 2007; Sacher et al., 2004) failed to find a correlation between neglect severity and the magnitude of the DD. Peripheral cueing was nonpredictive in Sacher et al. (2004), whereas it was both predictive and nonpredictive in Siéroff et al. (2007). Thus, it is possible that our paradigm based on central nonpredictive arrows is more effective in uncovering the correlation. Morrow and Ratcliff's conjecture that the DD improves with the resolution of neglect, indirectly confirmed by Losier and Klein, is thus directly supported by the positive correlation with neglect severity. The existence of a correlation with a decrease in the DD of patients whose left neglect ameliorated from the acute to the chronic phase was also shown in the study of Corbetta et al. (2005). Note that their study used central predictive arrows, thus mixing endogenous and reflexive orienting. On the basis of our results, it may be argued that the correlation is mainly driven by the reflexive component.

Our study confirmed that processing of validly cued targets is slower in the contralesional hemifield than in the ipsilesional one (e.g., Siéroff et al., 2007; Losier \& Klein, 2001). Notably, neglect patients were selectively slower on left valid trials in comparison to the patients without neglect. The left-right asymmetry for valid trials was closely related to neglect severity, as previously shown by Siéroff et al. (2007) with peripheral cueing.

\section{GENERAL DISCUSSION}

The present study showed that central nonpredictive cues that have directional meaning can trigger reflexive shifts of visuospatial attention in both healthy participants and in right brain-damaged patients. However, the comparison between the three types of directional cues revealed important differences. One first striking finding is that digits were ineffective in orienting attention when directly compared with eye gaze and arrows. The absence of cueing effect for digits seems to be at odds with the findings of Fischer et al. (2003), but it is consistent with the results of recent studies on healthy participants (Casarotti, Michielin, Zorzi, \& Umiltà, 2007; Galfano, Rusconi, \& Umiltà, 2006; Ristic \& Kingstone, 2006; Ristic, Wright, \& Kingstone, 2006). All these studies support the view that digits possess a low degree of automaticity in the hierarchy of cues that, although irrelevant for the task, can orient attention. Most notably, Casarotti et al. (2007) demonstrated that digit cues can nonetheless reliably produce attentional shifts when their relevance is increased (e.g., when digit identity must be reported).

Eye gaze and arrows reliably oriented attention in both healthy participants and right brain-damaged patients. Previous studies that separately investigated gaze cues (e.g., Driver et al., 1999; Friesen \& Kingstone, 1998) or arrow cues (Ristic \& Kingstone, 2006; Tipples, 2002; Hommel et al., 2001; Eimer, 1997) found similar orienting effects, whereas studies that directly compared the two types of cue (although in separate blocks) have not provided a firm conclusion (Ristic et al., 2002, 2007; Gibson \& Kingstone, 2006; Friesen et al., 2004; Ricciardelli, Bricolo, Aglioti, \& Chelazzi, 2002). A recent fMRI study suggested that orienting to gaze cues and arrow cues was supported by partially distinct cortical networks (Hietanen, Nummenmaa, Nyman, Parkkola, \& Hämäläinen, 2006). In our study, the differential effects emerged in the performance of neglect patients. Central nonpredictive arrow cues produced reflexive orienting and elicited the DD, whereas gaze cueing presented in the same conditions failed to consistently orient attention. At a first glance, the latter result would seem to be at odds with that of Vuilleumier (2002), who found that detection performance of right brain-damaged patients with neglect was modulated by centrally presented gazing faces. One possible explanation of this discrepancy relies upon the differences between the two paradigms. First, gaze processing might have been facilitated in Vuilleumier's study by the face context; second, attention orienting was triggered by moving eyes that are a much stronger cue compared with static eyes because they also convey a motion cue, as demonstrated in infants (Farroni, Johnson, Brockbank, \& Simion, 2000). The crucial finding, however, is that the effect of arrow cues in neglect patients consistently resembled patterns previously described as characterizing peripheral noninformative cues (for a thorough review, see Losier \& Klein, 2001). First, we found a DD at the shortest SOA (200 msec). Second, the DD was related to the presence of hemispatial neglect (and it was predicted by neglect severity). Third, responses to validly cued targets were slower in the left with respect to the right hemifield. Thus, our results challenge the conclusion that the DD would be robust only with peripheral cues (Losier \& Klein, 2001). These findings seem to challenge also the traditional dichotomy between peripheral-automatic versus central-voluntary orienting (for further discussion, see Gibson \& Kingstone, 2006). As a consequence, it is worth stressing that arrows should not be used as central predictive cues if the aim is to study voluntary (i.e., endogenous) orienting of attention (see also Kingstone, Smilek, Ristic, Friesen, \& Eastwood, 2003). Note that we failed to find a DD for gaze cues, but this can be attributed to the absence of gaze cueing effect for neglect patients. This issue is, therefore, left open to future studies. In the same 
vein, the possibility to obtain a DD with central predictive nondirectional cues (i.e., pure endogenous) is a matter of further research.

In summary, our results show that the reflexive attentional orienting triggered by the directional meaning of arrow cues resembles some features that were thought to characterize stimulus-driven (exogenous) orienting to noninformative peripheral cues. This does not imply equivalence between reflexive and exogenous orienting. Indeed, a dissociation between impaired reflexive orienting (for gaze cues) and spared exogenous orienting has been shown in a patient with frontal damage (Vecera \& Rizzo, 2006), suggesting that the former relies at least in part on components of the network subserving top-down control of attention. The performance of our left neglect patients was relatively impaired for orienting in the left hemifield compared with orienting in the right hemifield, consistently with previous studies that adopted peripheral cueing. According to the model of Corbetta and Shulman (2002), neglect patients' performance can be interpreted in terms of damage to the right-lateralized network that is devoted to the fast exogenous orienting toward salient environmental events and that serves as circuit breaker for the bilateral fronto-parietal network. Indeed, in our sample, TPJ (and more specifically the superior temporal gyrus) was the cortical area most often damaged in the $\mathrm{N}+$ group, whereas superior fronto-parietal areas were relatively spared.

Paradigms that minimize the voluntary components allow to investigate the "core deficit" in neglect patients rather than the recruitment of compensatory strategies based on spared voluntary orienting mechanisms. The use of central nonpredictive cues has been shown here to provide useful insights and to be complementary to the classic central and peripheral cueing paradigms.

\section{Acknowledgments}

We would like to thank all patients who took part in the study, Giovanni Scalambrin for helping in data collection, and Carlo Umiltà for methodological suggestions. We are grateful to Massimo Iannilli, Luca Ortolani, Carla Piubelli, Umberto Sansubrino, Ilaria Strumendo, and Marco Ferraro for referring patients under their care and for helpful comments. This study was supported by grants from MIUR (PRIN 2004 and PRIN 2006 to M. Z.) and from the European Commission (Marie Curie Research Training Network "Numeracy and Brain Development" to M. Z.).

Reprint requests should be sent to Marco Zorzi, University of Padova, Dipartimento di Psicologia Generale, Via Venezia 8, 35131, Padova, Italy, or via e-mail: marco.zorzi@unipd.it, web: http://ccnl.psy.unipd.it.

\section{REFERENCES}

Argyle, M., \& Cook, M. (1976). Gaze and mutual gaze. New York: Cambridge University Press.
Baron-Cohen, S. (1994). How to build a baby that can read minds: Cognitive mechanisms in mindreading. Cahiers de Psychologie/Current Psychology of Cognition, 13, 513-552. Bartolomeo, P., \& Chokron, S. (1999). Left unilateral neglect or right hyperattention? Neurology, 53, 2023-2027.

Bartolomeo, P., \& Chokron, S. (2002). Orienting of attention in left unilateral neglect. Neuroscience and Biobehavioral Reviews, 26, 217-234.

Bartolomeo, P., Sieroff, E., Decaix, C., \& Chokron, S. (2001). Modulating the attentional bias in unilateral neglect: The effect of the strategic set. Experimental Brain Research, 137, 432-444.

Bartolomeo, P., Thiebaut de Schotten, M., \& Doricchi, F. (2007). Left unilateral neglect as a disconnection syndrome. Cerebral Cortex, 17, 2479-2490.

Casarotti, M., Michielin, M., Zorzi, M., \& Umiltà, C. (2007). Temporal order judgement reveals how number magnitude affects visuospatial attention. Cognition, 102, 101-117.

Corbetta, M., Kincade, M. J., Lewis, C., Snyder, A. Z., \& Sapir, A. (2005). Neural basis and recovery of spatial attention deficits in spatial neglect. Nature Neuroscience, 8, 1603-1610.

Corbetta, M., \& Shulman, G. L. (2002). Control of goal directed and stimulus-driven attention in the brain. Nature Reviews Neuroscience, 3, 201-215.

Danziger, S., Kingstone, A., \& Rafal, R. D. (1998). Orienting to extinguished signals in hemispatial neglect. Psychological Science, 9, 119-123.

Dehaene, S., Bossini, S., \& Giraux, P. (1993). The mental representation of parity and number magnitude. Journal of Experimental Psychology: General, 122, 371-396.

D'Erme, P., Robertson, I., Bartolomeo, P., Daniele, A., \& Gainotti, G. (1992). Early rightwards orienting of attention on simple reaction time performance in patients with left-sided neglect. Neuropsychologia, 30, 989-1000.

Driver, J., Davis, G., Ricciardelli, P., Kidd, P., Maxwell, E., \& Baron-Cohen, S. (1999). Gaze perception triggers reflexive visuospatial orienting. Visual Cognition, 6, 509-540.

Egly, R., Driver, J., \& Rafal, R. D. (1994). Shifting visual attention between objects and locations: Evidence from normal and parietal lesion subjects. Journal of Experimental Psychology: General, 123, 161-177.

Eimer, M. (1997). Uninformative symbolic cues may bias visual-spatial attention: Behavioural and electrophysiological evidence. Biological Psychology, 46, 67-71.

Farah, M. J., Wong, A. B., Monheit, M. A., \& Morrow, L. A. (1989). Parietal lobe mechanisms of spatial attention: Modality-specific or supramodal? Neuropsychologia, 27, 461-470.

Farroni, T., Johnson, M. H., Brockbank, M., \& Simion, F. (2000). Infants' use of gaze direction to cue attention: The importance of perceived motion. Visual Cognition, 7, 705-718.

Fischer, M. H., Castel, A. D., Dodd, M., \& Pratt, J. (2003). Perceiving numbers causes spatial shifts of attention. Nature Neuroscience, 6, 555-556.

Friedrich, F. J., Egly, R., Rafal, R. D., \& Beck, D. (1998). Spatial attention deficits in humans: A comparison of superior parietal and temporal-parietal junction lesions. Neuropsychology, 12, 193-207.

Friesen, C. K., \& Kingstone, A. (1998). The eyes have it! Reflexive orienting is triggered by non-predictive gaze. Psychonomic Bulletin \& Review, 5, 490-495.

Friesen, C. K., \& Kingstone, A. (2003). Abrupt onsets and gaze direction cues trigger independent reflexive attentional effects. Cognition, 87, B1-B10. 
Friesen, C. K., Ristic, J., \& Kingstone, A. (2004). Attentional effects of counterpredictive gaze and arrow cue. Journal of Experimental Psychology: Human Perception and Performance, 30, 319-329.

Frischen, A., Bayliss, A. P., \& Tipper, S. P. (2007). Gaze cueing of attention: Visual attention, social cognition, and individual differences. Psychological Bulletin, 133, 694-724.

Frischen, A., Smilek, D., Eastwood, J. D., \& Tipper, S. P. (2007). Inhibition of return in response to gaze cues: The roles of time-course and fixation cue. Visual Cognition, 15, 881-895.

Galfano, G., Rusconi, E., \& Umiltà, C. (2006). Number magnitude orients attention, but not against one's will. Psychonomic Bulletin \& Review, 13, 869-874.

Gibson, B. S., \& Bryant, T. A. (2005). Variation in cue duration reveals top-down modulation of involuntary orienting to uninformative symbolic cues. Perception \& Psychophysics, 67, 749-758.

Gibson, B. S., \& Kingstone, A. (2006). Visual attention and the semantics of space: Beyond central and peripheral cues. Psychological Science, 17, 622-627.

Halligan, P. W., Fink, G. R., Marshall, J. C., \& Vallar, G. (2003). Spatial cognition: Evidence from visual neglect. Trends in Cognitive Sciences, 7, 125-133.

Hietanen, J. K., Nummenmaa, L., Nyman, M., Parkkola, R., \& Hämäläinen, H. (2006). Automatic attention orienting by social and symbolic cues activates different neural networks: An fMRI study. Neuroimage, 33, 406-413.

Hommel, B., Pratt, J., Colzato, L., \& Godijn, R. (2001). Symbolic control of visual attention. Psychological Science, 12, 360-365.

Karnath, H. O., Ferber, S., \& Himmelbach, M. (2001). Spatial awareness is a function of the temporal not the posterior parietal lobe. Nature, 411, 950-953.

Kingstone, A., Smilek, D., Ristic, J., Friesen, C. K., \& Eastwood, J. (2003). Attention researchers! It is time to take a look at the real world. Current Directions in Psychological Science, 12, 176-180.

Klein, R. M. (2000). Inhibition of return. Trends in Cognitive Sciences, 4, 138-147.

Klein, R. M. (2004). On the control of orienting. In M. I. Posner (Ed.), Cognitive neuroscience of attention (pp. 29-44). New York: Guilford Press.

Làdavas, E., Carletti, M., \& Gori, G. (1994). Automatic and voluntary orienting of attention in patients with visual neglect: Horizontal and vertical dimensions. Neuropsychologia, 32, 1195-1208.

Làdavas, E., Menghini, G., \& Umiltà, C. (1994). On the rehabilitation of hemispatial neglect. Cognitive Neuropsychology, 11, 75-95.

Losier, B. J. W., \& Klein, R. M. (2001). A review of the evidence for a disengage deficit following parietal lobe damage. Neuroscience and Biobehavioral Reviews, 25, $1-13$.

Luo, C. R., Anderson, J. M., \& Caramazza, A. (1998). Impaired stimulus-driven orienting of attention and preserved goal-directed orienting of attention in unilateral visual neglect. American Journal of Psychology, 111, 487-507.

Magni, E., Binetti, G., Padovani, A., Cappa, S. F., Bianchetti, A., \& Trabucchi, M. (1996). The Mini-Mental State Examination in Alzheimer's disease and multi-infarct dementia. International Psychogeriatrics, 8, 127-134.

McKee, D., Christie, J., \& Klein, R. (2007). On the uniqueness of attentional capture by uninformative gaze cues: Facilitation interacts with the Simon effect and is rarely followed by IOR. Canadian Journal of Experimental Psychology, 61, 293-303.
Mesulam, M. (1999). Spatial attention and neglect: Parietal, frontal, and cingulate contributions to the mental representation and attentional targeting of salient extrapersonal events. Philosophical Transactions of the Royal Society of London, Series B, 354, 1325-1346.

Mondini, S., Mapelli, D., Vestri, A., \& Bisiacchi, P. (2003). Esame Neuropsicologico Breve. Milano: Raffaello Cortina Editore.

Morrow, L. A., \& Ratcliff, G. (1988). The disengagement of covert attention and the neglect syndrome. Psychobiology, 16, 261-269.

Mort, D. J., Malhotra, P., Mannan, S. K., Rorden, C., Pambakian, A., Kennard, C., et al. (2003). The anatomy of visual neglect. Brain, 126, 1986-1997.

Müller, H. J., \& Rabbit, P. M. A. (1989). Reflexive and voluntary orienting of visual attention: Time course of activation and resistance to interruption. Journal of Experimental Psychology: Human Perception and Performance, 15, 315-330.

Nagel-Leiby, S., Buchtel, H. A., \& Welch, K. M. A. (1990). Cerebral control of directed attention and orienting saccades. Brain, 113, 237-276.

Okamoto-Barth, S., \& Kawai, N. (2006). The role of attention in the facilitation effect and another "inhibition of return." Cognition, 101, B42-B50.

Posner, M. I. (1980). Orienting of attention. Quarterly Journal of Experimental Psychology, 32, 2-25.

Posner, M. I., \& Cohen, Y. (1984). Components of attention. In H. Bouma \& D. Bowhuis (Eds.), Attention and performance $X$ (pp. 531-556). Hillsdale, NJ: Lawrence Erlbaum Associates.

Posner, M. I., Walker, J. A., Friedrich, F. J., \& Rafal, R. D. (1984). Effects of parietal injury on covert orienting of attention. Journal of Neuroscience, 4, 1863-1874.

Ptak, R., \& Schnider, A. (2006). Reflexive orienting in spatial neglect is biased towards behaviourally salient stimuli. Cerebral Cortex, 16, 337-345.

Ricciardelli, P., Bricolo, E., Aglioti, S. M., \& Chelazzi, L. (2002). My eyes want to look where your eyes are looking: Exploring the tendency to imitate another individual's gaze. NeuroReport, 13, 2259-2263.

Ristic, J., Friesen, C. K., \& Kingstone, A. (2002). Are eyes special? It depends on how you look at it. Psychonomic Bulletin G Review, 9, 507-513.

Ristic, J., \& Kingstone, A. (2006). Attention to arrows: Pointing to a new direction. Quarterly Journal of Experimental Psychology, 59, 1921-1930.

Ristic, J., Wright, A., \& Kingstone, A. (2006). The number line effect reflects top-down control. Psychonomic Bulletin and Review, 13, 862-868.

Ristic, J., Wright, A., \& Kingstone, A. (2007). Attentional control and reflexive orienting to gaze and arrow cues. Psychonomic Bulletin E Review, 14, 964-969.

Rorden, C., \& Brett, M. (2000). Stereotaxic display of brain lesions. Behavioural Neurology, 12, 191-200.

Sacher, Y., Serfaty, C., Deouell, L., Sapir, A., Henik, A., \& Soroker, N. (2004). Role of disengagement failure and attentional gradient in unilateral spatial neglect-A longitudinal study. Disability and Rehabilitation, 26, 746-755.

Schneider, W., Eschman, A., \& Zuccolotto, A. (2002). E-Prime reference guide. Pittsburgh, PA: Psychology Software Tools.

Siéroff, E., Decaix, C., Chokron, S., \& Bartolomeo, P. (2007). Impaired orienting of attention in left unilateral neglect: A componential analysis. Neuropsychology, 21, 94-113.

Snyder, J. J., \& Chatterjee, A. (2006). The frontal cortex and exogenous attentional orienting. Journal of Cognitive Neuroscience, 18, 1913-1923. 
Talairach, J., \& Tournoux, P. (1988). Co-planar stereotaxic atlas of the buman brain. Stuttgart: Thieme.

Tipples, J. (2002). Eye gaze is not unique: Automatic orienting in response to uninformative arrows. Psychonomic Bulletin \& Review, 9, 314-318.

Umiltà, C. (2001). Mechanisms of attention. In B. Rapp (Ed.), The handbook of cognitive neuropsychology (pp. 135-158). Philadelphia: Psychology Press.

Vecera, S. P., \& Rizzo, M. (2006). Eye gaze does not produce reflexive shifts of attention: Evidence from frontal-lobe damage. Neuropsychologia, 44, 150-159.

Vuilleumier, P. (2002). Perceived gaze direction in faces and spatial attention: A study in patients with parietal damage and unilateral neglect. Neuropsychologia, 40, 1013-1026.
Wilson, B., Cockburn, J., \& Halligan, P. W. (1987). The Behavioural Inattention Test. Bury St. Edmunds: Thames Valley Test Company.

Zorzi, M., Mapelli, D., Rusconi, E., \& Umiltà, C. (2003). Automatic spatial coding of perceived gaze direction is revealed by the Simon effect. Psychonomic Bulletin $\mathcal{E}$ Review, 10, 423-429.

Zorzi, M., Priftis, K., Meneghello, F., Marenzi, R., \& Umiltà, C. (2006). The spatial representation of numerical and non-numerical sequences: Evidence from neglect. Neuropsychologia, 44, 1061-1067.

Zorzi, M., Priftis, K., \& Umiltà, C. (2002). Brain damage: Neglect disrupts the mental number line. Nature, 417, 138-139. 